International Journal of Advanced Trends in Computer Science and Engineering

Available Online at http://www.warse.org/IJATCSE/static/pdf/file/ijatcse196922020.pdf

https://doi.org/10.30534/ijatcse/2020/196922020

\title{
Problems of Development of a Cloud-Oriented Educational Environment of the University
}

\author{
${ }^{1}$ Akhmetov B., ${ }^{2}$ Lakhno V., ${ }^{2}$ Tkach Y., ${ }^{1}$ Adranova A., ${ }^{3}$ Zhilkishbayeva G. \\ ${ }^{1}$ Abai Kazakh National Pedagogical University, Kazakhstan, bakhytzhan.akhmetov.54@mail.ru, \\ assel.adranova@gmail.com \\ ${ }^{2}$ National University of Life and Environmental Sciences of Ukraine, Ukraine, lva964@ gmail.com \\ ${ }^{3}$ Yessenov University, Aktau, Kazakhstan, gulnaz.zhilkishbayeva@ yu.edu.kz
}

\begin{abstract}
The article shows that at the current stage of development of modern universities, it is necessary to ensure the functioning of the educational environment, which will fully realize the conditions for academic mobility, communication and cooperation between research and teaching staff (RTS) and students. That is, it is necessary to introduce a cloud-oriented educational environment of universities (COEE) for more efficient organization of the academic community, which brings together both RTS and students. It is shown that for the effective implementation of COEE in universities it is necessary to develop new models that reflect the main components of COEE, processes and the relationships between them. There is proposed a multi-cloud COEE model based on the principles of modular arithmetic. The proposed modification of COEE will increase the reliability of storage and processing of data shared by the academic community of several universities at once, both for scientific work and for exchanging experience in introducing advanced teaching methods and new educational and methodological developments of university research and teaching staff who participate in the project. There are analyzed the models of reliable storage of large volumes of data for COEE. There are shown the advantages of models based on modular arithmetic over models based on a positional number system. So, for example, the probability of COEE failure on the basis of an excess system of residual classes (RCS) is approximately 4,5-5 times less than for a system based on replica storage.
\end{abstract}

Key words: cloud-oriented educational environment of universities, modular arithmetic, excess system of residual classes, reliable data storage.

\section{INTRODUCTION}

A significant increase in the amount of information used for learning has become a distinctive feature of leading universities around the world. Due to the work of leading universities, for example, such as Oxford, Cambridge (Great Britain), Stanford, California Technological, Harvard (USA), etc., which, in addition to educational activities, conduct active scientific researches over the past decades, hundreds of terabytes of various theoretical and experimental data have been accumulated in the most different areas of human activity [1], [2]. Moreover, the volume of obtained data will continue to increase steadily and with a high probability will reach exabyte marks in the coming decades. Following the paradigm of globalization of modern education, the information obtained in the course of research becomes available to all members of the scientific community, wherever members of research teams are geographically located. Of course, this does not apply to research results aimed at improving the defense capability and security of the state, but this aspect of storing research results is not considered in this article. In this situation, the tasks associated with reliable storage and data management become fundamental. Moreover, the lack of ways for adequate solution of them in the future will lead to significant economic and functional losses for many universities that do not seek to develop cloud technologies, as one of the most promising ways to solve this problem.

We should that, according to many researchers [2]-[5], in order to increase the reliability of data processing and storage, computer network architectures with distributed data storage should be actively introduced. And the technical aspect of this problem is no less important than the pedagogical methods and techniques used to prepare specialists in various fields of activity at universities.

The relevance of the research on the subject of the article is due to the fact that today the requirements are constantly growing both for the effective technical and hardware component of the educational process organization, and for its quality. Today there are new opportunities for the comprehensive development of students of the XXI century, new, more effective information and communication technologies (ICT), in particular cloud-oriented educational environments (COEE), are developing rapidly. The introduction of COEE in the higher education system will allow the creation of such management and educational structures of universities that will provide not only unlimited access to electronic educational resources, but also the latest conditions of communication and cooperation for those higher educational institutions (HEI) where there are no powerful IT departments and financially -technical resources. In turn, while organizing the COEE, aspects of the problem related to the construction of highly reliable schemes for 
storing and processing large-dimension data are not sufficiently considered [6].

Innovative changes in the HEI contribute to the comprehensive development of the student's personality in the implementation of the paradigm of continuing education of research and teaching staff (RTS), to the formation of the values of a democratic society.

In a modern society, open to all and aimed at the development of education, a key role belongs to the RTS, which is entrusted with the comprehensive development of students, the disclosure of their potential and the formation of a successful person and specialist. Along with this, it is necessary that the university has professional and competent RTS with a high level of motivation, always ready to help students. The professional activities of the university's RTS are becoming more complicated: new technological and pedagogical technologies are being introduced, the content of education is changing, new activities are appearing, which, in turn, require the systematic development of information competencies (IC) not only of all subjects of education, but also of technical specialists involved in the implementation of new IT in the educational process.

\section{REVIEW AND ANALYSIS OF PREVIOUS STUDIES}

In recent years, interest in education has increased significantly, and RTS are increasingly turning to Internet services to use ICTs for communication, cooperation and corporate work, and the rapid development of cloud services has become a leading trend in solving the problems of educational mobility of all participants in the educational process.

The solution of these problems are socially significant tasks of both technical and pedagogical science.

Let note that the basis of the study of COEE is a number of scientific results that reflect the introduction of ICT in universities [6]-[8].

A theoretical analysis of scientific works by leading scientists in the field of education, a study of the experience of ICT and cloud services use in the educational process, and university management, indicates the presence of contradictions between [9], [10]:

- the growing influence of ICT on the development of higher education and the lag in theoretical and methodological research in problems of their systematic use in the educational process;

- significant didactic potential of COEE and the absence of theoretically substantiated models and effective methods of its use in universities;

- the increasing demands of society for the organization of the educational process at universities and the low level of ICT and COEE use;

- the presence of a significant amount of programmatic, educational, methodological and didactic support for the educational process and the lack of shared access to it;

- significant technological potential of COEE and low educational mobility of participants of the educational process;

- the intensive development of ICT and the speed of updating the content of educational programs, in particular on technical and information disciplines, ensuring the formation of IC students.

Therefore, the problem of the scientific and theoretical justification and development of COEE, taking into account the practical needs of teachers and the requirements of society for the organization of the educational process, is not fully resolved. The latter, in turn, negatively affects the level of development of the IC of the subjects of educational process and ensuring their educational mobility [10], [11].

Significant scientific contribution to the theory and practice of cloud computing was made by such scientists as G. Alonso [12], R. Buyya [4] and others.

In works [4], [8], [12], [13], there were considered theoretical and practical aspects of increasing the reliability and availability of data stored in cloud systems, as well as various architectural solutions used for cloud computing. However, it is worth noting that these approaches are mainly designed for large players on the cloud technology market [14], [15], and often do not take into account the specifics of COEE, for which often the priority is not the speed of encoding and decoding information in the cloud, but the reliability of the system . The last circumstance is dictated by the fact that the COEE often stores the results of many years of research conducted by the RTS and students and their loss may lead to a loss of priority in new innovative research areas, which today determine the face of leading world universities and institutes.

In this regard, as was shown in [16]-[18], it seems appropriate to analyze the possibility of creating a COEE on an architecture that involves the use of residual classes in a data storage subsystem. This will provide reliable and faultresistant data storage in the cloud system.

Using the system of residual classes (RCS) [19]-[21] and the data distribution scheme in COEE, it is possible to create new schemes for storing, distributing, and processing data in university cloud environments. And such an approach will ensure high reliability, authenticity and constant availability of information for the entire academic community without reference to geographical location.

Therefore, the relevance of the study on the development of the theoretical and methodological foundations for designing a cloud-oriented educational environment of the university is determined by the need to formulate a new direction of applied research on the theory and methodology of developing and using COEE, aimed at the development of IC of RTS and students of higher educational institutions.

\section{THE PURPOSE}

The purpose of the study is to analyze the problems of developing the theoretical and methodological foundations for designing a cloud-oriented educational environment of the university (COEE) and to justify the structural scheme of its interaction with the methodological centers of the ministry based on the use of cloud technologies, as well as increase of the fault-resistance and reliability of data processing and storage schemes in COEE with adjustable redundancy. 
In order to achieve the purpose of the study, it is necessary to solve the following tasks:

to develop a conceptual model of cloud data storage architecture for a large university, in the context of analyzing COEE as a large-scale distributed storage system consisting of many independent storage servers, as well as to compare approaches for data storage in COEE based on data replication and RCS;

to analyze the development problems of cloud COEE not only in the context of a technical task, but as an example of the structural interaction of the ministry's methodological centers with university's RTS using cloud technologies;

to conduct testing and modeling of distributed long-term storage of data with a large capacity in the cloud of universities.

\section{METHODS AND MODELS}

\subsection{Conceptual model of the cloud data storage} architecture

The concept of COEE is based on two components:

1) the need to integrate disconnected data in a single repository, access to which has not only RTS and students of this university, but scientists and methodologists of other educational institutions;

2) the need to separate the data sets and applications that are used in the process of operational processing, and, for example, can be used in applications.

The conceptual cloud data storage (CDS) scheme for universities is presented in the form of the following scheme, see Figure 1.

Data collected from various sources is stored in a repository. Description of relevant data is in the repository.

In our study, CDS is considered as a large-scale distributed data storage system. Moreover, CDS may include many independent servers for storing data or other information arrays.

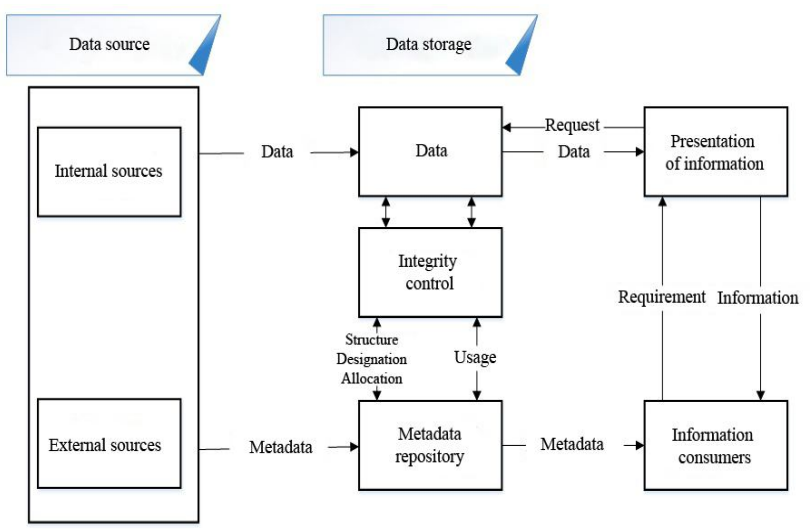

Figure 1: Conceptual model of the CDS architecture

\subsection{A cloud data storage model for a large university based on an excess residual class system}

Using a data separation scheme (DSS), which is based on the RCS for COEE, allows to separate data between the cloud storage facilities of universities. In this case, part of the data can be stored in different $\mathrm{k}$ cloud storage. The number of parts may vary depending on the specific requirements for the COEE. If there are $\mathrm{k}$ parts, you can restore the stored data. Moreover, each part separately does not mean anything. Data can only be restored in case where all $\mathrm{k}$ parts are assembled together. The disadvantage is that in case of loss/error in one of the parts, there is no possibility to restore the stored data.

In order to eliminate this disadvantage, specialists from the universities of Sh. Yesenov (Republic of Kazakhstan), together with the Department of Computer Systems and Networks of the National University of Life and Environmental Sciences of Ukraine (Ukraine), used an excess system of residual classes [20]. That is, creating a data storage and processing system for COEE, there was used the opportunity to use a different number of modules of excess RCS. The system used $n=k+r$ of clouds, where $k$ working clouds and $r$ - control clouds. If it is necessary to perform a complete data backup, then it is assumed that $(\mathrm{k} \leq \mathrm{r})$. If partial data backup is needed then $\mathrm{k}>\mathrm{r}$, see Figure 2.

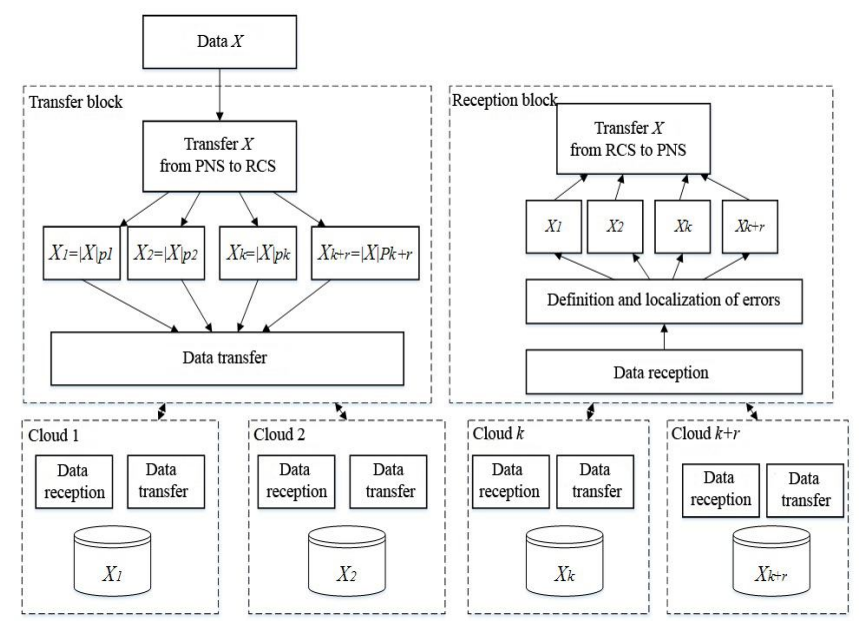

Figure 2: A model for storing data in COEE using an excess RCS where PNS - a positional number system

For this model of data storage in COEE, designed for the interaction of both large universities with each other, as well as for the interaction with cloud storages of ministries and departments, the state space corresponds to the workload of a regular cloud server (ClSer). Therefore, each ClSer can be set by its own capacity - $x_{i}$. Then the characteristics of the entire system are described as follows:

$$
X=\bigcup_{i=1}^{n} x_{i} \text {. }
$$

Each user, for example, RTS, a methodologist or a university student, is specified as a parameter $y_{i}$. Moreover, $y_{1}-$ time unit cost of the COEE operation; $y_{2}-$ time taken to detect errors; $y_{3}-$ time taken to correct the error (or $y_{3}\left(P_{m}\right)-$ where $P_{m}$ - the probability of data loss). Then, $Y=\bigcup_{i=1}^{n} y_{i}-$ characteristics of the user. 
The ratio $\left(x_{i} / y_{i}\right)$

will determine the relative

effectiveness of the $i-$ th cloud server of each of the universities that participate in the program.

Solving this problem allows to get the benefits of joint access of students and RTS to the cloud data of individual universities, and thereby to increase not only the effectiveness of scientific cooperation and learning outcomes, but also overall reliability, fault-resistance, and performance of COEE while minimizing the cost of renting the computing power of third-party providers.

\subsection{Problems of development of a cloud-oriented educational environment of the university}

Any learning cycle, including at universities, contains three main components: purpose, content and learning process. Therefore, each learning cycle as an element of a whole system should provide:

actualization of supporting knowledge and motivation of students to learn;

the formation of new concepts and methods of action;

the ability to apply what is learned to solve problems of different difficulty levels;

and etc.

Designing the activities of learning subjects in COEE is the development of complex network communication, see Figure 3. Therefore, we consider designing for various aspects of the educational process at the university.

The activities of RTS and students in COEE can be divided according to the following criteria:

mass character: individual, group, collective;

the presence of subjects of learning: online and offline;

training technology: synchronous and asynchronous;

technologies for learning organization: independent,

design, laboratory, practical;

assessment: self assessment, self-analysis, reflection;

activity: active learning, passive learning;

direction: practical, theoretical.

The activities of learning subjects in COEE are implemented in order to meet the following needs: learning, personal development. Educational needs should encourage the student to increase his level of knowledge and for interaction with other subjects of learning.

The needs of students' personal development are satisfied for:

development of own abilities;

development of subject competencies;

interaction with other subjects.

The interaction between the RTS and students can be carried out by:

checking and evaluating various tasks;

conducting seminars;

implementation of projects.

During the preparation of tasks for practical and laboratory studies, the RTS develops the tasks:

general - for all parallel groups;

group - for one group; fours)

for small groups - for students to work in pairs (triples,

individual - for each student.

The student should carry out such educational activities in COEE as:

to send completed tasks to the RTS, for example, by email;

to perform tasks in shared documents;

to provide RTS with the task for the public use.

Assessment of educational achievements of students is carried out as: individual, group.

During the classes, students can perform individual work using various services or use in the process of organizing the implementation of creative tasks a conference communication system for communication with the RTS.

Nowadays, with every year, the role of ICT in the interaction of the RTS with students is increasing. Therefore, there is an urgent need to ensure effective interaction between various categories of RTS, as well as university methodologists, heads and employees of university laboratories, in organizing access to regulatory and methodological materials. This is necessary for their storage, distribution of methodological recommendations, instructions, for examinations and quality assessment of didactic developments of the RTS, for organization of certification of educational courses, in particular, placed in the cloud, presentation of the results at various conferences and competitions, etc.

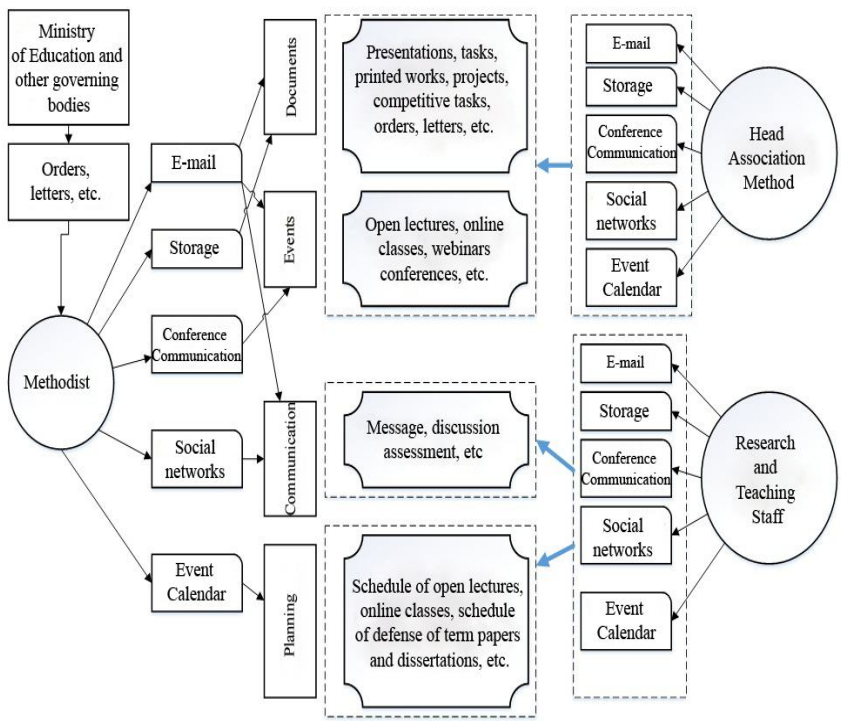

Figure 3: The structure of the interaction of the ministry's methodological centers with university RTS using cloud technologies

The use of modern ICT, for example, such as Office365 or Google Docs, makes it possible to solve a number of problems, one of which is the creation and development of dynamic virtual methodological subject associations (VMSA), providing integrated interaction with scientific and methodological centers of leading universities.

One of the components of the educational process and the educational environment, in particular, providing a solution 
to such a problem as students' quality control of knowledge, are methodological associations of RTS in the relevant industry, for example, RTS who specialize in IT, mathematics, physics, and chemistry. It is possible to improve the quality of the methodological work of the university at all its levels from the university methodological association of the RTS to the industrial one using COEE. Due to the development and distribution of cloud computing at universities, new opportunities for RTS appear, namely, the formation of virtual methodological subject associations.

Using COEE in professional work, methodological associations receive a number of advantages:

access to own materials and documents without reference to the place and time;

the ability to use video and audio files online, without additional load on the computer;

Lync communication with other educational institutions (conducting online lectures, trainings, round tables);

the possibility of forming the path of their own professional development;

fundamentally new opportunities for organizing research, project activities and adapting educational material to real life;

fundamentally new opportunities for transferring knowledge (online lectures with leading experts in a particular field of knowledge, webinars, integrated practical classes, cooperative laboratory work, online communications with RTS and students from other cities or countries).

\section{THE RESULTS OF EXPERIMENTAL STUDIES}

In order to confirm the possibility of providing reliable and safe data storage in the COEE, there were carried out experimental studies on the basis of the proposed model.

As the mathematical basis for fault-resistant data storage in the COEE, there were used the basic provisions of the residual classes system (RCS) [20]-[23].

To analyze the coding and decoding speed of data in different series of experiments, there were used data processing centers of three universities: the National University of Life and Environmental Sciences of Ukraine (Kiev), the Chernigov National Technological University (Chernigov, Ukraine), the data center of Sh. Esenov University (Aktau, Kazakhstan). Indicators of reliability of data storage for various COEE systems of university are presented in table 1 .

Table 1: HDD failure probability for various data storage schemes in COEE

\begin{tabular}{|c|c|}
\hline Storage system & System failure probability (max) \\
\hline Replica creation & $4,1 \cdot 10^{-12}$ \\
\hline Excess RCS $(6,2)-(6,3)$ & $2,52 \cdot 10^{-25}$ \\
\hline Excess RCS $(8,2)$ & $4,0 \cdot 10^{-12}$ \\
\hline
\end{tabular}

The Figures 4-7 present the results of experimental studies. So the Figure 4 shows the probability of information loss in COEE for various cases of RCS redundancy.
The Figure 5 shows a histogram showing the data encoding rate $(\mathrm{Mb} / \mathrm{s})$ in COEE.

The Figure 6 shows the diagram for analysis and comparative assessment of the probability of failure-free operation of COEE, which was created using the RCS algorithm and data replicas stored in the university data processing center.

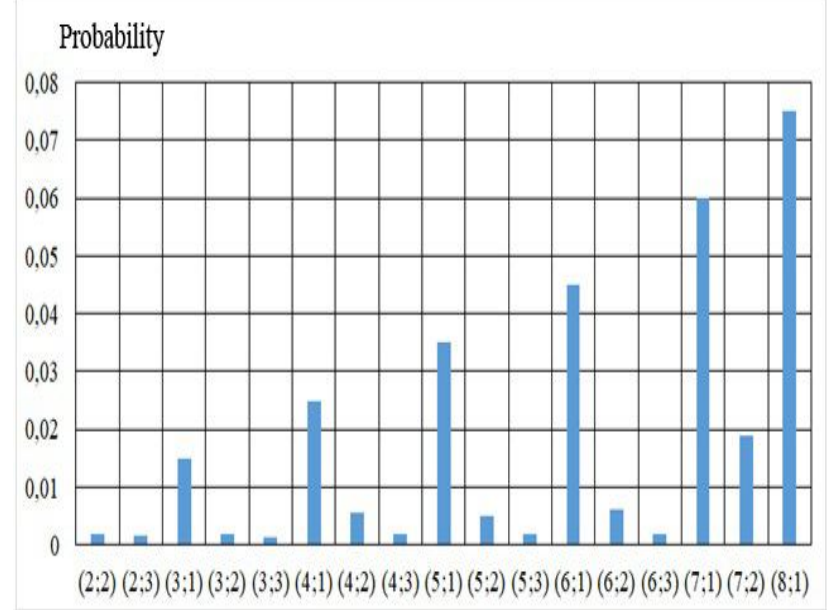

Figure 4: Probability of information loss

\section{Data encoding rate $(\mathrm{Mb} / \mathrm{s})$}

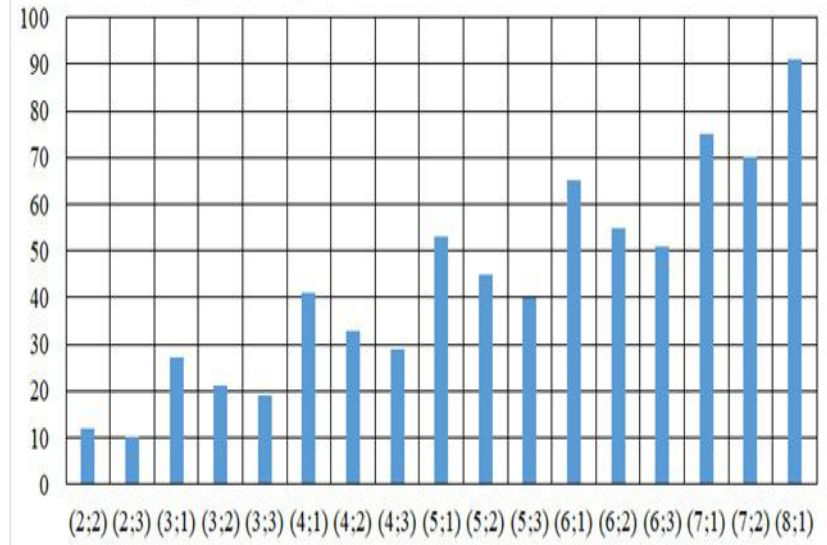

Figure 5: Data encoding rate $(\mathrm{Mb} / \mathrm{s})$

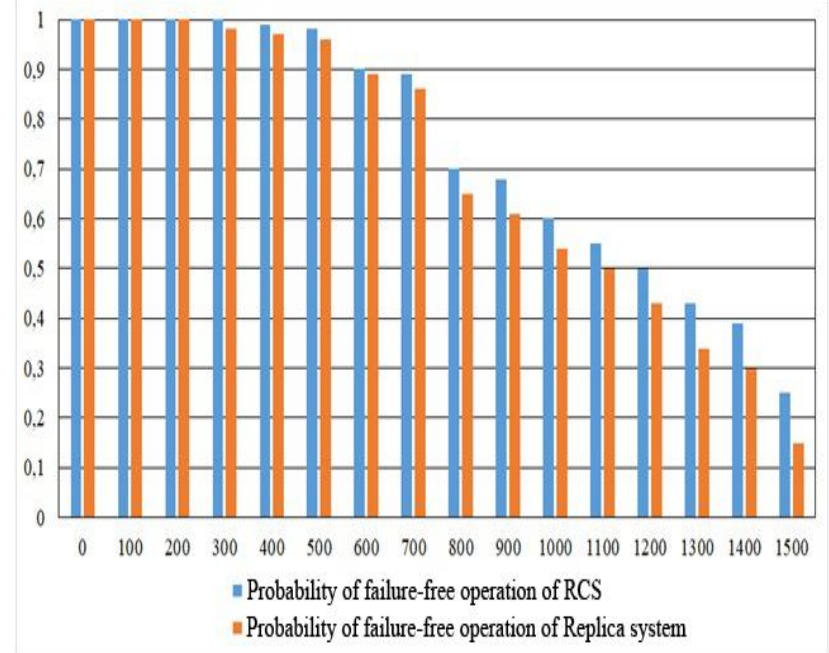

Figure 6: Diagram of a comparative assessment of the probability of failure-free operation of COEE, constructed using the RCS algorithm and data replicas 
Since the COEE servers for various universities and other structures that were examined during the study are created on different hardware components, the parameters of the HDD failure statistics used on university servers were analyzed, see table 2. In case of cloud computing or the necessity of constant data storage in the cloud, there should be considered the possibility of joint failure of several disks, although this event is unlikely.

Table 2: Failure statistics of hard drives used in COEE for 2 universities of Ukraine and Kazakhstan

\begin{tabular}{|c|c|c|}
\hline Manufacturer & Volume & Failure probability \\
\hline HGST & $2 \mathrm{~Tb}$ & 0,00000051 \\
\hline WDC & $6 \mathrm{~Tb}$ & 0,000151 \\
\hline Seagate & $4 \mathrm{~Tb}$ & 0,0000163 \\
\hline
\end{tabular}

The calculation of the reliability indicator of a university multi-cloud system, which is based on excess RCS, is carried out by the formula:

$$
P_{0}=\sum_{i=n-k+1}^{n} C_{n}^{i} \cdot P_{d}^{i} \cdot q^{n-1},
$$

where $q=1-P_{d}, P_{d}-$ the probability that one COEE server will fail.

Calculation results for $k=\overline{2,8}, \quad r=1,2,3$ are shown on Figure 7.

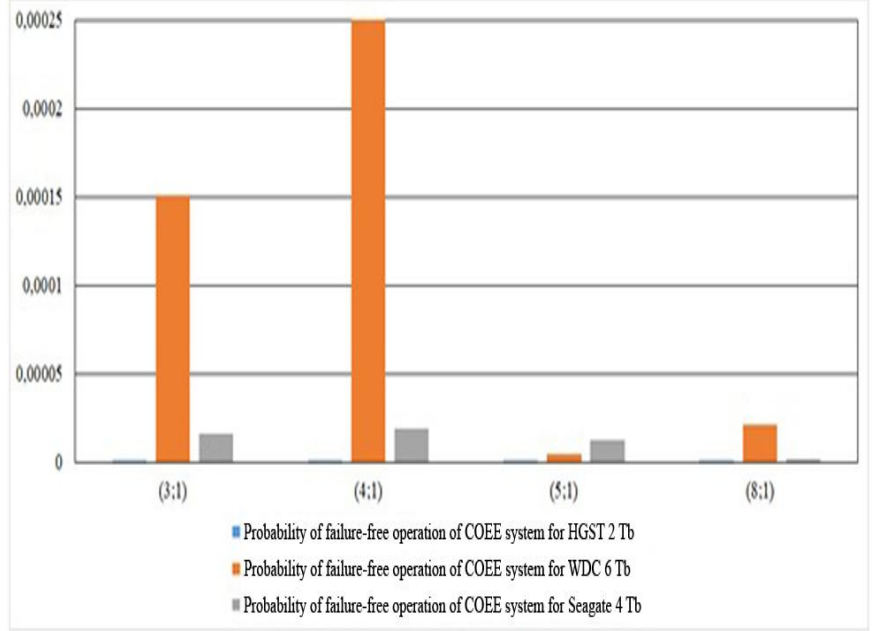

Figure 7: Cloud System Failure Probabilities

Creation of a single-level COEE using an excess RCS will improve the reliability of data storage. And the use of models of joint COEEs will allow to create not only highly reliable COEEs, but also allow to increase the efficiency of the academic community of all universities that are ready for such a format of cooperation.

\section{DISCUSSION}

Assessment of the reliability of the data processing and storage parameters in COEEs, which is created on the basis of RCS, and comparing them with similar positional systems showed that the first ones have significant advantages. This can be explained by the fact that the effect of element-wise sliding reservation is present in COEE. Also, using RCS, the ratio of equipment redundancy decreased.

The analysis of the obtained dependences showed the advantages and greater reliability of the algorithms for storing and processing data based on RCS. The latter provide a significant increase in the reliability of COEE without the need to use additional hardware costs while reducing redundancy.

According to the results of experimental and computational studies, it was concluded that COEE based on RCS allows storing data with high reliability compared to the currently used data storage systems based on replicas.

\section{GRATITUDES}

The authors are grateful to the staff and management of the data storage centers of the National University of Life and Environmental Sciences of Ukraine (Kiev), Chernigov National Technological University (Chernigov, Ukraine), Yessenov University (Aktau, Kazakhstan) for the provided statistical information and practical assistance in testing the technologies for creating and deploying cloud-oriented educational environments that unite the academic community and students of these universities.

\section{CONCLUSION}

At the current stage of development of modern universities, it is necessary to ensure the functioning of the educational environment, which will fully realize the conditions for academic mobility, communication and cooperation between scientists, research and teaching staff (RTS) and students. It is necessary to introduce such models of the educational environment, which will make it possible to fully satisfy the demands of university scientists and RTS on organizing scientific work and conducting classes of a new type, enhancing the educational activities of students, the formation of information competencies and the comprehensive development of personality. Such opportunities are provided by the use of a cloud-oriented educational environment of the university (COEE).

For the effective implementation of COEE in universities, it is necessary to develop new models that reflect the main components of COEE, processes and the relationships between them. A promising model seems to be the COEE model, which is based on a cloud-oriented educational environment with the active use of methods of interactive learning, academic communication, cooperation and corporate work between RTS and students on the one hand, as well as on the interaction of RTS and students from different universities, primarily leading in one or another subject area. The implementation of intensive forms and teaching methods in COEE is an essential factor in increasing motivation for educational and cognitive activities, the level of emotional perception of data by students and masters of universities. The COEE model for the interaction of scientific and methodological centers of the Ministry of Education with universities opens new possibilities for the scientific and methodological support of 
the educational process, determines the ways of interaction both at the level of RTS, the university methodological association of RTS, and at the level of a city, region or several states.

There is proposed a multi-cloud COEE model based on the principles of modular arithmetic. A modification of the COEE in order to increase the reliability of storage and processing of data shared by the academic community of several universities at once, both for scientific work and for exchanging experience in introducing advanced teaching methods and new educational and methodological developments of university research and teaching staff who participate in the project.

The models of reliable storage of large volumes of data for COEE are analyzed. There are shown advantages of models based on modular arithmetic over models based on a positional number system. So, for example, the probability of COEE failure based on an excess RCS is approximately 4,55 times less than for a system based on replica storage.

\section{REFERENCES}

1. S. Agadzhanova, A. Tolbatov, O. Viunenko, O. Tolbatova. Using cloud technologies based on intelligent agent-managers to build personal academic environments in E-learning system, In 2017 2nd International Conference on Advanced Information and Communication Technologies (AICT), IEEE, pp. 92-96, 2017. https://doi.org/10.1109/AIACT.2017.8020073

2. Y. Nosenko, M. Shyshkina, V. Oleksiuk. Collaboration between research institutions and university sector using cloud-based environment, arXiv preprint arXiv:1807.08741, 2018.

3. J. Cao, Z. Li, Q. Luo, Q. Hao, T. Jiang. Research on the Construction of Smart University Campus Based on Big Data and Cloud Computing, In 2018 International Conference on Engineering Simulation and Intelligent Control (ESAIC), IEEE, pp. 351-353, 2018.

https://doi.org/10.1109/ESAIC.2018.00088

4. S. Chaudhary, G. Somani, R. Buyya. Research advances in cloud computing, Springer Singapore, 2017.

https://doi.org/10.1007/978-981-10-5026-8

5. E. Samerkhanova, E. Krupoderova, K. Krupoderova, L. Bakhtiyarova, A. Ponachugin, T.Kanyanina. Developing an information educational environment based on cloud technologies, Journal of Entrepreneurship Education, Vol. 20(3), pp. 1-9, 2017.

6. D. Altman. Power and Community. Organiztaionnal and Cultural Responses to AIDS, London : Taylor \& Francis, pp. 190, 1994.

7. D.W. Denton. Enhancing instruction through constructivism, cooperative learning, and cloud computing, TechTrends, vol. 56(4), pp. 34-41, 2012. https://doi.org/10.1007/s11528-012-0585-1

8. Dictionary.com [Electronic resource]. - Text. data. Access mode:http://dictionary. reference.com/browse/ modeling (date of access 16.09.15).
9. J.H. Dahooie, A.S. Vanaki, N. Mohammadi. Choosing the Appropriate System for Cloud Computing Implementation by Using the Interval-Valued Intuitionistic Fuzzy CODAS Multiattribute Decision-Making Method (Case Study: Faculty of New Sciences and Technologies of Tehran University), IEEE Transactions on Engineering Management, 2019.

10. A. Pascalev. 2567 OHRP meets ToS: Cloud-based technologies in human subject research, Journal of Clinical and Translational Science, vol. 2(S1), pp.85, 2018. https://doi.org/10.1017/cts.2018.294

11. N. Antonopoulos. Cloud Computing. Principles, Systems and Applications, London : Springer, pp.379, 2010.

12. G. Alonso. FPGAs in data centers, Queue, vol.16(2), pp. 52-57, 2018.

13. H.E. Samra, A.S. Li, B. Soh, M.A. AlZain. A CloudBased Architecture for Interactive E-Training, In Cloud Security: Concepts, Methodologies, Tools, and Applications, IGI Global, pp. 1379-1392, 2019.

14. M. Watfa. Cloud computing and E-learning: Potential pitfalls and benefits, In 2016 Sixth International Conference on Innovative Computing Technology (INTECH), IEEE, pp. 140-144, 2016. https://doi.org/10.1109/INTECH.2016.7845128

15. H. Rezaei, B. Karimi, S.J. Hosseini. Effect of cloud computing systems in terms of service quality of knowledge management systems, Lecture Notes on Software Engineering, vol. 4(1), pp.73, 2016.

16. V. Agrawal, A. Agrawal, S. Agarwal. Assessment of factors for e-learning: an empirical investigation, Industrial and Commercial Training, vol. 48(8), pp. 409-415, 2016. https://doi.org/10.1108/ICT-03-2016-0015

17. U. Tikhonov, V. Lakhno, E. Skliarenko, O. Stepanenko, K. Dvirnyi. Development of ontological approach in e-learning when studying information technologies, Eastern-European Journal of Enterprise Technologies, Vol.5 (2), pp. 13-20, 2016.

18. L. Lytvynenko, O. Nikolaievskyi, V. Lakhno, E. Skliarenko. Development of knowledge-oriented system of machine translation based on the analyticsynthetic text processing, Eastern-European Journal of Enterprise Technologies, vol. 1 (2), pp. 15-24, 2017.

19. V.A. Lakhno, O.Y. Nikolaievskyi, E. V. Skliarenko, L.O. Lytvynenko. Models and tools for automatization of the linguistic research, Journal of Theoretical and Applied Information Technology, vol. 95(5), pp. 989-999, 2017.

20. A. Yanko, S. Koshman, V. Krasnobayev. Algorithms of data processing in the residual classes system, In 2017 4th International Scientific-Practical Conference Problems of Infocommunications. Science and Technology (PIC S\&T), IEEE, pp. 117-121, 2017.

21. I.A. Kalmykov, A.V. Veligosha, D.I. Kaplun, D.M. Klionskiy, V.V. Gulvanskiy. Parallel-pipeline implementation of digital signal processing techniques based on modular codes, In 2016 XIX 
IEEE International Conference on Soft Computing and Measurements (SCM), IEEE, pp.213-214, 2016.

https://doi.org/10.1109/SCM.2016.7519731

22. M.L. Priyanka, S.Rajeshwari, K.Ashwini. An Expert model for DNA Based Encryption Technology using Cloud Computing, International Journal of Advanced Trends in Computer Science and Engineering (IJATCSE), Vol. 8, No.1.3, pp.15-18, 2019.

https://doi.org/10.30534/ijatcse/2019/0381.32019

23. B. Madhuravani, N.Chandra Sekhar Reddy, K.Sai Prasad, B.Dhanalaxmi, V. Uma Maheswari. Strong and Secure Mechanism for Data Storage in Cloud Environment, International Journal of Advanced Trends in Computer Science and Engineering (IJATCSE), Vol. 8, No.1.3, pp.29-33, 2019.

https://doi.org/10.30534/ijatcse/2019/0681.32019 